\title{
A INSERÇÃO DA ARQUITETURA MODERNA PAULISTA NO CENTRO HISTÓRICO DE PRESIDENTE PRUDENTE: O PAÇO MUNICIPAL
}

\author{
Geovana Gea Nogueira, Hélio Hirao \\ Universidade Estadual Paulista - FCT - UNESP. Arquitetura e Urbanismo, Presidente Prudente, SP. E-mail: \\ cv.geovana@gmail.com \\ PIBIC-Reitoria.
}

\section{RESUMO}

Esta pesquisa está inserida num projeto em desenvolvimento no Departamento de Planejamento Urbanismo e Ambiente da Faculdade de Ciências e Tecnologia (FCT) da Universidade Estadual Paulista (UNESP), Campus de Presidente Prudente, denominada: "Persistência no espaço urbano dos edifícios da década de 1940 em Presidente Prudente SP". Esta pesquisa desenvolve o inventário arquitetônico do antigo e do novo Paço Municipal. O primeiro edifício da década de 1940, com características do Art Déco, foi substituído no final da década de 1960 por outra construção modernista, de autoria de Wilson Jorge, arquiteto com fortes influências da obra de Vilanova Artigas, mestre da Arquitetura Moderna Paulista. O edifício modernista é de interesse de preservação, já demonstrada por teses acadêmicas. Através da análise da documentação histórico-documental, levantamento métrico-arquitetônico, estado de conservação, documentação fotográfica atual e visitas in loco permitiram a verificação dos desígnios projetados e sua apropriação socioespacial, na perspectiva de relacioná-los com a teoria da restauração para indicar diretrizes para sua salvaguarda em seu contexto urbano atual.

Palavras-chave: Inventário, escola paulista de arquitetura, salvaguarda, Paço Municipal, Presidente Prudente.

\section{THE INSERTION OF SÃO PAULO MODERN ARCHITECTURE IN THE HISTORIC CENTER OF PRESIDENTE PRUDENTE: THE MUNICIPAL PALACE}

\begin{abstract}
This research is part of a project under development in Urban Planning and Environment Department of the Faculdade de Ciências e Tecnologia (FCT) of Universidade Estadual Paulista (UNESP), Campus of Presidente Prudente, named: "persistence in the urban space of the buildings of the Decade of 1940 in Presidente Prudente SP". This research develops the architectural inventory of old and new Municipal Palace. The first building of the Decade of 1940 with features of Art Deco, was replaced in the late 1960 by another modernist construction by Jorge Wilson, architect with strong influences from the work of Vilanova Artigas, master of modern architecture in São Paulo. The modernist building is of interest of preservation, as demonstrated by academic theses. Through the analysis of historical documentations, metric-lifting documentary, architectural conservation status, current photographic documentation and on-the-spot visits have allowed verification of designs designed and their social-spatial appropriation, in order to relate them with the theory of restoration to indicate the guidelines for the protection in their current urban context.
\end{abstract}

Keywords: inventory, paulista School of architecture, safeguarding, Municipal Palace, Presidente Prudente. 


\section{INTRODUÇÃO}

A Arquitetura Brasileira é representada por um grande número de arquitetos com diferentes expressões, influências, características históricas e culturais por eles consideradas em suas concepções. Um dos momentos de destaque foi a arquitetura moderna, que modificou o panorama artístico e cultural de sua época.

Neste contexto, os arquitetos, ao executarem estes novos princípios valeramse de técnicas e representações artísticas capazes de expressarem este momento histórico, tais como a eliminação de ornatos, a estrutura aparente, a planta "livre", a ideia de protótipo e a possibilidade de reprodução industrial muito mais que opções formais (CAVALCANTI, 2006).

No Brasil, de acordo com (SEGAWA, 2002) a arte moderna brasileira irá se desenvolver no pós-guerra, no período denominado Guerra Fria. Neste contexto, a modernização era necessária para um país atrasado como o Brasil. No campo da construção a tecnologia, a tecnologia aplicada, a industrialização, a pré-fabricação e o uso de pré-moldados representava o pensamento nacional-desenvolvimentista da época: "Para essa mentalidade, o domínio da tecnologia própria constituía um atributo objetivo do grau de pregresso do país. A industrialização da construção foi uma preocupação constante [...]" (SEGAWA, 2002,
p.149).O brutalismo não foi um movimento isolado no âmbito mundial. No Brasil, suas características podem ser encontradas pelo amplo território nacional, porém para fins desta pesquisa, iremos discorrer sobre a linha paulista cujo maior representante foi o arquiteto João Batista Vilanova Artigas.

Para Artigas, a arquitetura moderna não era apenas um estilo, mas uma causa. O arquiteto, para ele, possuía uma função social e que esta se sustentaria no projeto como emancipação política e ideológica e no desenho como um veículo de expressão.

Através deste discurso e da análise de suas obras, percebemos que Vilanova Artigas expressava em sua arquitetura os seus ideais e anseios. Artigas fez da forma construída a expressão do seu comportamento estrutural, caminhando no sentido de evidenciar os esforços tectônicos da construção e seus vínculos dinâmicos. Pois, em suas palavras, o papel da arquitetura é expor os contrastes e contradições ideológicas implicadas na formalização de suas obras, ao invés de resolvê-los harmoniosamente (ARTIGAS, 2004). Daí a sua severa moral construtiva, que procura deixar evidentes as marcas do processo produtivo na obra acabada. Marcas estas visíveis tanto no tratamento bruto do concreto aparente, quanto na explicitação da mecânica da construção, legível nas cargas e nos empuxos que determinam o desenho dos pilares. (FORTY; ANDREOLI, 2004). 
Parte do imaginário modernista alcançou o interior dos estados através de planos governamentais, como o Plano de Ação do Governo do Estado de São Paulo (PAGE) implantado pelo governador Carvalho Pinto em 1959. Esse plano reproduziu em grandes escalas o conceito de modernização através da construção de obras públicas (principalmente escolas) de arquitetura moderna, e através de arquitetos do interior que tiveram contato com este movimento nas capitais, e o reproduziram em suas cidades de origem. Estas duas vertentes podem ser encontradas na cidade de Presidente Prudente. A primeira ilustrada pela Escola Municipal João Franco de Godoy (Navio), do arquiteto João Clodomiro de Abreu, e a segunda pelo Paço Municipal de Presidente Prudente, do arquiteto Wilson Edson Jorge - obra escolhida para o desenvolvimento desta pesquisa.

Entretanto, muitas obras deste período que sobreviveu com o decorrer dos anos encontram-se descaracterizadas e em péssimo estado de conservação. No caso do Paço Municipal, há a visível saturação do espaço devido ao fato do espaço edifício não ter acompanhado as demandas surgidas com o crescimento da cidade. Devido este problema, o que encontramos ao visitar a prefeitura é um grande número de secretarias e departamentos acumulados em uma pequena área, além de um edifício modificado de sua configuração inicial.

Este trabalho tem como eixo principal, o estudo do prédio do Paço Municipal de Presidente Prudente, sua identidade, centralidade, importância como edifício público e principalmente como importante referencial da Arquitetura Moderna no interior oeste paulista. Através desta investigação, pretende-se debater os meios que tornem possível a conservação, manutenção e preservação de um edifício modernista que tem em si várias representações. Desta forma, objetiva estabelecer diretrizes de um projeto de reabilitação arquitetônica que atenda as atuais demandas da Prefeitura Municipal, mantendo as funções de governo na área central da cidade.

\section{PROCEDIMENTOS METODOLÓGICOS}

Através da análise da documentação histórico-documental, levantamento métricoarquitetônico, estado de conservação, documentação fotográfica atual e visitas in loco permitiram a verificação dos desígnios projetados e sua apropriação socioespacial do prédio modernista do Paço Municipal de Presidente Prudente, na perspectiva de relacioná-los com a teoria da restauração para a formação de subsídios para indicar diretrizes para sua salvaguarda em seu contexto urbano atual. 


\section{RESULTADOS}

Desde a sua construção, o edifício passou por alterações tais como a ausência de elementos presentes no projeto original e a implantação do Teatro Municipal no subsolo do Paço, segundo (HIRAO, 2008, p. 153):

"Aspectos importantes da concepção inicial não foram concretizados. 'Brises soleil' (protetores solares) estavam previstos em três faces do edifício, menos na parte frontal, fundamental para garantir o conforto térmico dos seus usuários. [...] Outro elemento ausente na construção foi um volume (prisma de base triangular) situado junto à avenida para se presidirem solenidades e desfiles.".

Ao longo dos anos, o edifício passou e passa por diversas modificações que o descaracterizaram. Paredes internas de concreto armado foram pintadas, assim como os pilares que receberam a cor branca na Câmara Municipal e a cor azul na Prefeitura. As esquadrias das vedações ainda são as originais, porém encontram-se em péssimo estado, algumas estão já corroídas e outras ainda foram pintadas na cor preta. A abertura zenital, formada por uma parede circular e que iluminava o hall de entrada foi vedada, e o espelho d'agua tão característico deu lugar a um estacionamento destinado aos funcionários do Paço. Devido à ausência dos "Brises soleil", já excluído desde a construção do prédio, muitos aparelhos de ar-condicionado e películas protetoras na cor roxa foram colocadas para evitar o calor. Todas essas alterações resultaram em um edifício "colcha de retalhos", que abriga diversas alterações que comprometem a concepção arquitetônica modernista.

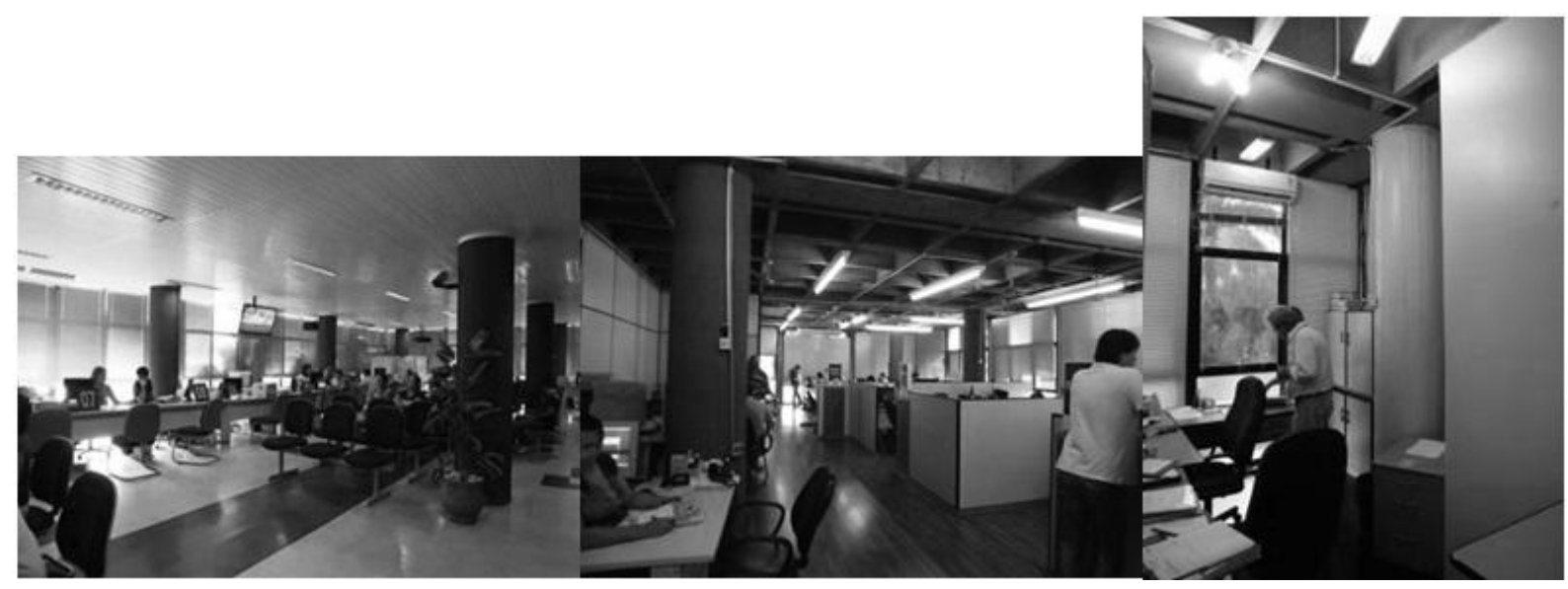

Figura 1. Situação atual do Paço Municipal respectivamente, atendimento ao público na Prefeitura, Secretaria de Planejamento e Câmara Municipal.

Fonte: NOGUEIRA, 2014. 


\section{DISCUSSÃO}

O edifício do Paço Municipal, construído na década de 1960, não atende às necessidades das atividades atuais. Os espaços internos encontram-se saturados para receber as novas demandas, a acessibilidade inexiste em algumas partes, bem como, as reformas realizadas ao longo dos anos, que foram mal sucedidas, produzindo descaracterizações que não consideraram a preexistência construída.

A preservação e manutenção do prédio modernista com características brutalistas no centro histórico da cidade corre sérios riscos. Existe a intenção da própria Prefeitura Municipal de transferir o Paço para a periferia da cidade, carente de equipamentos urbanos e infraestrutura. Essa mudança deve provocar um efeito gradativo de esvaziamento das atividades que caracterizam o centro. Em entrevista, no dia 15 de Abril de 2014, com o Secretário Municipal de Planejamento, este reafirmou a proposta de abrir uma licitação para a venda do edifício e com esse recurso construir o novo Centro Administrativo de Presidente Prudente.

Contrário às intenções dos atores políticos, este projeto defende a manutenção das atividades de governo no centro histórico da cidade, que mesmo com o atual processo de redefinição da centralidade intraurbana
(SPOSITO, 2001) conduzindo a uma segmentação e segregação socioespacial (WHITACKER, 1997), a manutenção destas atividades garante "uma certa ideia de cidade" (GOMES, 2011) como lugar do encontro dos diferentes, das diversidades, contemplando o acesso pela maioria das pessoas da riqueza social, da vida democrática e dos benefícios da evolução da ciência e tecnologia.

Nesse sentido, o estudo encaminha diretrizes para a permanência das atividades relacionadas com o atendimento ao público uma vez que, esta área constitui-se no lugar mais acessível para seus habitantes, viabilizada pela infraestrutura viária e de transportes públicos existentes, além do atributo da vitalidade e identidade urbana.

Por outro lado, no edifício brutalista de Jorge, as diretrizes de intervenção arquitetônica encaminham para a manutenção do caráter da edificação, para (YAMAKI, 2008) caráter são as "características fundamentais" daquilo que deve permanecer como valorização do patrimônio arquitetônico e cultural. Desse modo, os princípios projetuais relacionados com a continuidade do espaço público e privado, ou seja, a continuidade da Praça Nove de Julho com o edifício deve ser preservada, tanto quanto as iluminações zenitais, o espelho d'água, que qualificam 
essa ambiência. Instalar Brises soleil móveis com características atuais, para a contenção térmica do edifício.

As necessidades de novos espaços devem ser concebidas em um anexo num terreno adjacente, com características contemporâneas, valorizando o edifício brutalista e garantindo a permanência de um dos principais suportes materiais da memória da cidade.

Assim, o encaminhamento para o debate desta produção arquitetônica modernista brutalista no interior paulista passa pela preocupação da sua preservação no espaço urbano da cidade contemporânea.

A rigidez espacial do desígnio brutalista dificulta modificações no edifício que não alterem seus princípios projetuais originais e, com a rapidez das transformações dos modos de vida, comprometem sua permanência e salvaguarda.

\section{CONCLUSÕES}

O contexto da cidade, onde apresenta fortes relações com o ideal de progresso e desenvolvimento, possuí grandes influências da sociedade patriarcal, burguesa e conservadora que influenciaram nas transformações de uso e apropriação do edifício moderno, com se verificam nas inúmeras alterações realizadas no edifício do Paço Municipal. Entretanto, apesar das mudanças ocorridas, a forma arquitetônica do edifício deixa de forma evidente o seu caráter público, através da rampa que dá acesso livre à rua, alguns espaços que ainda permanecem abertos, caracterizando a obra como uma praça suspensa. A população acaba vivenciando esses espaços, em momentos como manifestações, eventos públicos, etc., quando esse espaço é apropriado pela população pela sua intenção original e o seu desígnio de certa forma se concretiza.

Em relação ao atual estado de preservação da obra modernista, há a necessidade de adaptação das atividades atuais e a preservação de um edifício tão importante para a cultura e história da cidade. Para tal é necessário que o Poder Público realize as demandas necessárias, possibilitando a manutenção e permanência das atividades do Paço Municipal no centro histórico de Presidente Prudente, como também a conscientização pela comunidade do seu valor urbano e arquitetônico para a preservação deste importante edifício brutalista.

\section{REFERÊNCIAS}

ARTIGAS, V. Os caminhos da Arquitetura Moderna. In: ARTIGAS, R.; ARTIGAS, V.; LIRA, J. T.C. Caminhos da Arquitetura. São Paulo: COSACNAIFY, 2004, p. 35-50.

CAVALCANTI, L. Moderno e Brasileiro: A história de uma nova linguagem na arquitetura (1930-60). Rio de Janeiro: Jorge Zahar Ed, 2006. 
ANDREOLI, E; FORTY, A. Europa - Brasil: Viagem de ida e volta. In: ANDREOLI, Elisabetta; FORTY, Adrian. Arquitetura Moderna Brasileira. Londres: Phaidon Press, Introdução, p.8-19.

GOMES, M. A.A.F. Preservação e Urbanismo: encontro, desencontros e muitos desafios. In: GOMES, M A.A. F; CORREA, E. L. (Orgs.). Reconceituações contemporâneas do patrimônio. Salvador: EDUFBA, 2011, p. 129144.

HIRAO, H. Arquitetura moderna paulista, imaginário social urbano, uso e apropriação do espaço. 2008. 224 f. Tese (Doutorado em Geografia) - Faculdade de Ciências e Tecnologia, Universidade Estadual Paulista, Presidente Prudente.

SEGAWA, H. Arquiteturas no Brasil 19001990. 2. ed. São Paulo: Ed. USP, 2002.

SPOSITO, M. E.B. Novas formas comerciais e redefinição da centralidade intraurbana. In: SPOSITO, M. E.B. (Org.). Textos e contextos para a leitura geográfica de uma cidade média. Presidente Prudente: FCT/Unesp GAsPERR, 2011.

WHITACKER, A. M. A produção do espaço urbano em Presidente Prudente: uma discussão sobre a centralidade urbana. 1997. 316 p. Dissertação (Mestrado em Geografia) - Faculdade de Ciências e Tecnologia, Universidade Estadual Paulista.

YAMAKI, H. Caráter de edificações históricas: elementos de identificação. Londrina:

Edições Humanidades, 2008.

Recebido para publicação em 06/08/2014

Aceito em 14/09/2014 